\title{
Preparation of a New Class of Telechelic Polyamides with Amino Groups from Bicyclic Oxalactam
}

\author{
Kazuhiko Hashimoto and Hiroshi Sumitomo \\ Faculty of Agriculture, Nagoya University, \\ Chikusa-ku, Nagoya 464, Japan \\ (Received February 12, 1983)
}

\begin{abstract}
KEY WORDS Bicyclic Oxalactam / 8-Oxa-6-azabicyclo[3.2.1]octan-7-one / Ring-Opening Polymerization / Telechelic Amino Group / Polyamide / Macromer /
\end{abstract}

Bicyclic oxalactam, 8-oxa-6-azabicyclo[3.2.1]octan-7-one (abbreviated as BOL, 1) is so highly polymerizable that at room temperature, its polymerization yields the high-molecular-weight polyamide. $^{1-5}$ Simultaneous film casting on a plate is also be readily possible. ${ }^{2,3,6,7}$ The resulting hygroscopic polyamide membrane has excellent permeability forward water and allows for the permselectivity of solutes of various sizes in an aqueous solution..$^{3,6-10}$

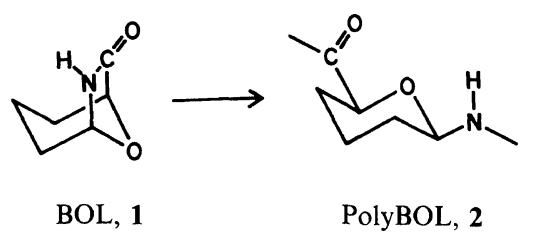

Since the registered trademark of macromer (oligomer having polymerizable functional endgroup(s)) was presented by Milkovich (1974), ${ }^{11}$ several macromers have been prepared using the ring-opening polymerization method. ${ }^{12-17}$ Earlier telechelic prepolymers having various functional groups, by which condensation polymers can be formed, are also regarded as macromers. We wish to describe the synthesis of a new type of polyamide macromers having telechelic amino groups through the anionic polymerization of BOL.

\section{EXPERIMENTAL}

\section{Reagents}

BOL was prepared by the same procedure re- ported earlier, ${ }^{2,3,6}$ and stored over phosphorus pentoxide in vacuo until use. Potassium pyrrolidonate and $N$-acetyl-8-oxa-6-azabicyclo[3.2.1]octan-7-one (abbreviated as K-Pyrdn and $N$-acetyl BOL, respectively) were prepared as described in the literature. ${ }^{2,18,19}$ Dimethyl sulfoxide $\left(\mathrm{Me}_{2} \mathrm{SO}\right)$ was dried over calcium hydride and distilled under reduced pressure. Tolylene-2,4-diisocyanate (TDI) was distilled in high vacuum and stored in a closed vessel until use. Ethylenediamine (EDA) was dried over calcium hydride, distilled and stored in the same way as TDI.

\section{Polymerization of BOL Followed by Amination of the Resulting Polyamide Chain Ends \\ Under a dry nitrogen atmosphere BOL, K-Pyrdn,} and $\mathrm{Me}_{2} \mathrm{SO}$ were placed in a flask and a $\mathrm{Me}_{2} \mathrm{SO}$ solution of $N$-acetyl BOL was added to the mixture with stirring and kept at $25^{\circ} \mathrm{C}$. After the polymerization an excess of EDA was directly added to the polymerization solution and the flask was allowed to stand in a constant-temperature bath. Volatile components were evacuated under reduced pressure and the residue was poured into a large amount of acetone. The resulting colorless polymer was collected on a glass filter, washed again with acetone, and dried in vacuo.

\section{Characterization}

${ }^{1} \mathrm{H}$ and ${ }^{13} \mathrm{C}$ NMR spectra were recorded, respectively, on a JEOL JNM-MH-100 highresolution spectrometer operating at $100 \mathrm{MHz}$ at room temperature and a JNM-FX-100 Fourier 
transform spectrometer operating at $25 \mathrm{MHz}$ at $60^{\circ} \mathrm{C}$. The UV spectrum was taken with a JASCO UVIDEC-1 spectrophotometer.

\section{Determination of Terminal Groups}

The amino group in the polyBOL was titrated with $0.02 N$ periodic acid in acetic acid under a nitrogen atmosphere using crystal violet as an indicator. ${ }^{20}$ The carbonyl group in the polyBOL in the $\mathrm{Me}_{2} \mathrm{SO}$-dimethylformamide mixed solvent was also determined by titration with $0.02 \mathrm{~N}$ sodium methoxide in the benzene-methanol $(1: 1, \mathrm{v} / \mathrm{v})$ mixed solvent using thymol blue as an indicator. ${ }^{20}$ The activator residue was determined by UV spectroscopy. The molecular extinction coefficient was assumed to be the same as that of the model compound, 2,4-bis $\left(N^{\prime}\right.$-propylureido)toluene prepared from TDI and $n$-propylamine.

\section{RESULTS AND DISCUSSION}

The anionic polymerization of BOL 1 using TDI as an activator, takes place by means of both growing ends of $N$-acyllactam as shown in equations 2 and 3 unless side reactions take place.
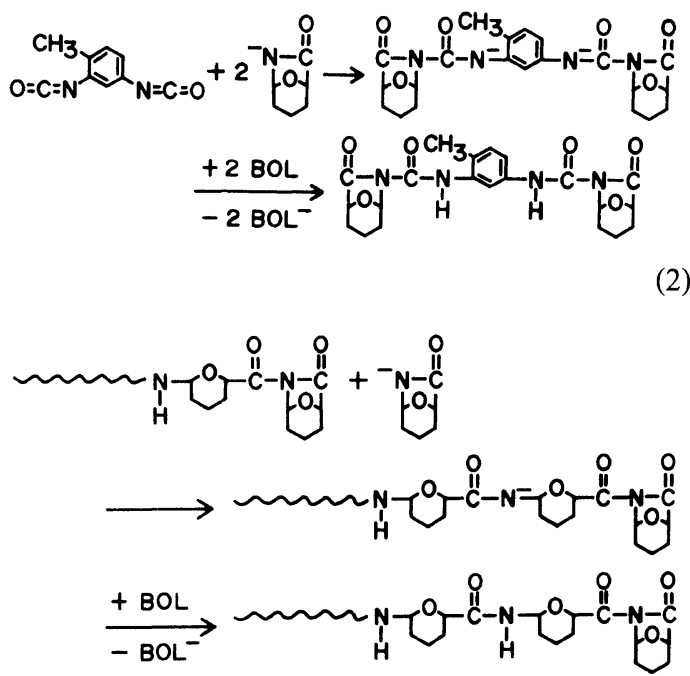

(3)

After polymerization, an excess of EDA was added directly to the polymerization mixture in order to introduce amino groups at the polymer ends (eq 4).

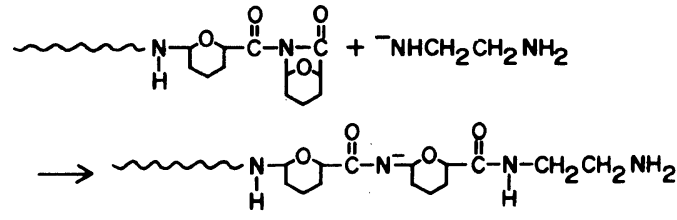

Growing Chain Ends of PolyBOL

First, the terminal groups and activator residue in the higher-molecular-weight polyBOL chain, which was terminated with water following polymerization, were characterized in order to determine whether $N$-acetyllactams were attached to the growing chain ends during polymerization (Table I).

The observed content of the amino groups suggests that the water-terminated polyBOL contained the polymer chain of structure 3 .

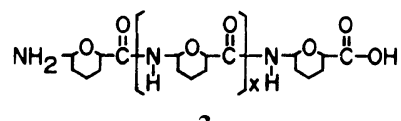

Polymerization can probably be initiated by attack of the BOL anion not only on the activator but also on the BOL monomer, since a slight amount of activator was used in these runs in order to obtain higher-molecular-weight polyBOL.

The number of carboxyl groups in polyBOL obtained by the TDI-initiated polymerization was almost equal to the sum of the amino groups and twice amount of activator residue. This means that the resulting polyBOL is a mixture of polymer chains having structures 3 and $\mathbf{4}$.

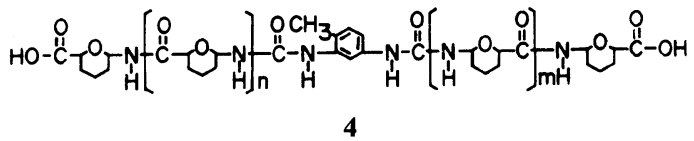

On the other hand, the polyBOL obtained by the $N$ acetyl BOL-initiated polymerization can be regarded as a mixture of those shown in $\mathbf{3}$ and $\mathbf{5}$, because in the run, the number of carboxyl group was equal to the sum of the amino groups and activator residue.

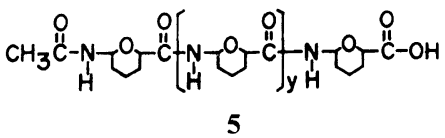

Polymer J., Vol. 15, No. 7, 1983 
Table I. Estimation of the terminal structures of higher-molecular-weight polyBOL from the number of functional groups ${ }^{\mathrm{a}}$

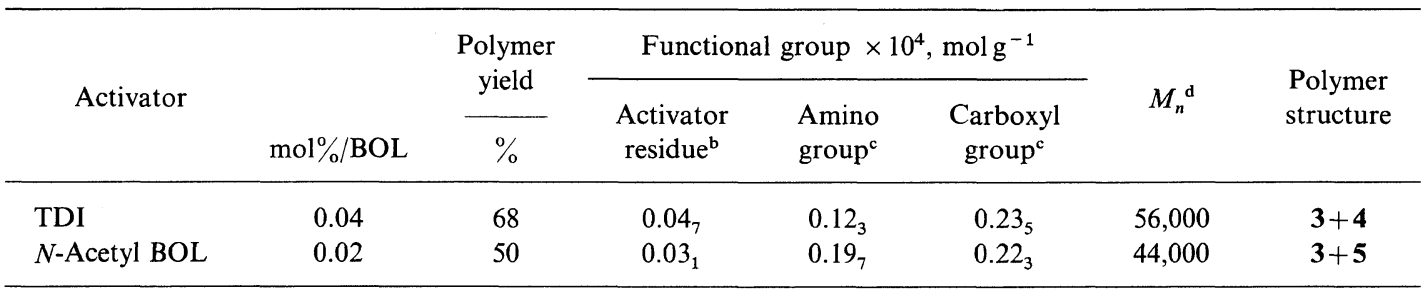

a Polymerization conditions: K-Pyrdn, $1 \mathrm{~mol} \%$ to $\mathrm{BOL}$; mole ratio of $\mathrm{Me}_{2} \mathrm{SO}$ to $\mathrm{BOL}$, 5.6; temperature, $25^{\circ} \mathrm{C}$; time, $24 \mathrm{~h}$; terminated with water.

b Estimated from the initial amount of the activator and the polymer yield assuming that all the activator was consumed in initiating the polymerization.

c Determined by volumetric titration.

d Estimated from terminal group content.

Table II. Reaction of $N$-acetyl-BOL with ethylenediamine

\begin{tabular}{|c|c|c|c|c|c|c|}
\hline \multirow{2}{*}{ Solvent } & [N-Acetyl BOL] & \multirow{2}{*}{$\frac{[\mathrm{EDA}]}{\mathrm{moll}^{-1}}$} & \multirow{2}{*}{$\frac{\text { Temp }}{{ }^{\circ} \mathrm{C}}$} & \multirow{2}{*}{$\frac{\text { Time }}{\min }$} & \multirow{2}{*}{$\begin{array}{c}\begin{array}{c}\text { Conversion } \\
\text { of EDA }\end{array} \\
\frac{\%}{\%}\end{array}$} & \multirow{2}{*}{$\begin{array}{c}\text { Probability of } \\
\text { attack of EDA } \\
\text { on lactam carbonyl } \\
\text { in } N \text {-acetyl BOL }\end{array}$} \\
\hline & $\mathrm{moll}^{-1}$ & & & & & \\
\hline $\mathrm{Me}_{2} \mathrm{SO}$ & 0.60 & 0.26 & 27 & 10 & 45 & - \\
\hline $\mathrm{Me}_{2} \mathrm{SO}$ & 0.60 & 0.26 & 27 & 170 & 81 & 0.72 \\
\hline $\mathrm{Me}_{2} \mathrm{SO}$ & 0.60 & 0.26 & 27 & 1440 & 100 & 0.74 \\
\hline $\mathrm{Me}_{2} \mathrm{SO}$ & 0.67 & $0.21^{\mathrm{a}}$ & 27 & $<10$ & 100 & 0.66 \\
\hline
\end{tabular}

a Sodium hydride was added to ethylenediamine by $4 \mathrm{~mol} \%$.

These results suggest that the growing chain ends were comprised of acyllactams during polymerization, as shown in eq 3 .

The resulting polyBOL was so hygroscopic that its molecular weight could not be determined by vapor pressure osmometry, but was evaluated on the number of observed terminal end groups as shown in Table I.

Model Reaction of the Growing Chain End with EDA

The reaction of $N$-acetyl BOL, which can be regarded as a model compound of the growing chain end, with EDA in $\mathrm{Me}_{2} \mathrm{SO}$ was followed by ${ }^{1} \mathrm{H}$ NMR spectroscopy. The spectra showed that the amino group of EDA attacked either carbonyl group in $\mathrm{N}$-acetyl BOL.

As for the reaction with the growing ends of the higher-molecular-weight polyBOL (eq 4), however, both attacks should give rise essentially to the same polyamide molecules telechelated with amino groups. More noteworthy are the facts that this reaction proceeds quantitatively and is accelerated by the addition of a small amount of base on EDA as shown in Table II.

\section{Preparation of Telechelic PolyBOL with Amino Groups}

After BOL was anionically polymerized in $\mathrm{Me}_{2} \mathrm{SO}$ at $25^{\circ} \mathrm{C}$ using TDI as an activator, excess EDA was directly added to the solution under various conditions as shown in Table III.

In the ${ }^{13} \mathrm{C}$ NMR spectrum of the resulting polyBOL were found the peaks assigned to the activator residue and terminal amino groups as shown in Figure 1. In addition peaks $h_{1}$ and $i_{2}$ show that their groups are linked to the internal and terminal repeating units in the polyBOL chain (6) respectively. 
Table III. Anionic polymerization of BOL followed by reaction with ethylenediamine ${ }^{\mathrm{a}}$

\begin{tabular}{|c|c|c|c|c|c|c|c|c|c|c|}
\hline \multirow{3}{*}{$\frac{\mathrm{TDI}}{\mathrm{mol} \%}$} & \multirow{3}{*}{$\begin{array}{c}\begin{array}{c}\text { Polymerization } \\
\text { time }\end{array} \\
\frac{\mathrm{h}}{}\end{array}$} & \multicolumn{2}{|c|}{ Reaction with $\mathrm{EDA}^{\mathrm{b}}$} & \multirow{2}{*}{\multicolumn{2}{|c|}{$\begin{array}{l}\text { Acetone insoluble } \\
\text { polymer }\end{array}$}} & \multicolumn{3}{|c|}{ Functional group $\times 10^{4}, \mathrm{~mol} \mathrm{~g}^{-1}$} & \multirow{3}{*}{$M_{n}{ }^{\mathrm{e}}$} & \multirow{3}{*}{ Aminolysis } \\
\hline & & \multirow{2}{*}{$\frac{\text { Temp }}{{ }^{\circ} \mathbf{C}}$} & \multirow{2}{*}{$\frac{\text { Time }}{\text { day }}$} & & & Activator & Amino & Carboxyl & & \\
\hline & & & & $\mathrm{g}$ & $(\%)$ & residue $^{c}$ & group $^{d}$ & group $^{d}$ & & \\
\hline 4 & 1 & 25 & 5 & 1.97 & (77) & $3.48(3.64)$ & 8.43 & $<0.02$ & 2,370 & 0.21 \\
\hline 1.8 & 3 & 40 & 1 & 1.87 & (74) & $1.85(1.93)$ & 12.4 & $<0.02$ & 1,610 & 2.3 \\
\hline 0.04 & 24 & 60 & 0.25 & 2.14 & (84) & $-\quad(0.037)$ & 31.9 & $<0.02$ & 630 & 109 \\
\hline 0.04 & 24 & - & - & $1.73^{\mathrm{g}}$ & (68) & $-(0.047)$ & $0.12_{3}$ & $0.23_{5}$ & 56,000 & - \\
\hline
\end{tabular}

a BOL, $2.54 \mathrm{~g}$; K-Pyrdn, $1 \mathrm{~mol} \%$ to $\mathrm{BOL} ; \mathrm{Me}_{2} \mathrm{SO}, 16.9 \mathrm{~g}$; polymerization temperature, $25^{\circ} \mathrm{C}$.

b Mole ratio of EDA to BOL, $3-4$.

${ }^{c}$ Determined by UV spectroscopy. The molecular extinction coefficient of 2,4-bis $\left(N^{\prime}\right.$-propylureido)toluene was used for that of the activator residue. The figure in parenthesis was estimated from the amount of activator used.

d Determined by volumetric titration.

${ }^{e}$ Estimated from the content of terminal groups.

f Frequency of aminolysis during the reaction with EDA.

g Water insoluble polymer. 


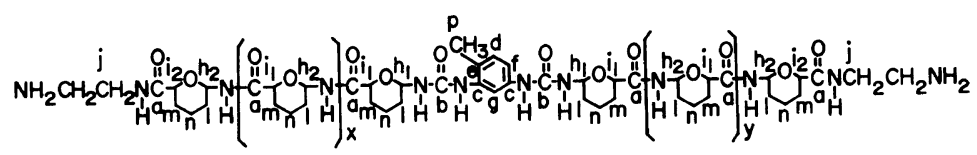

6

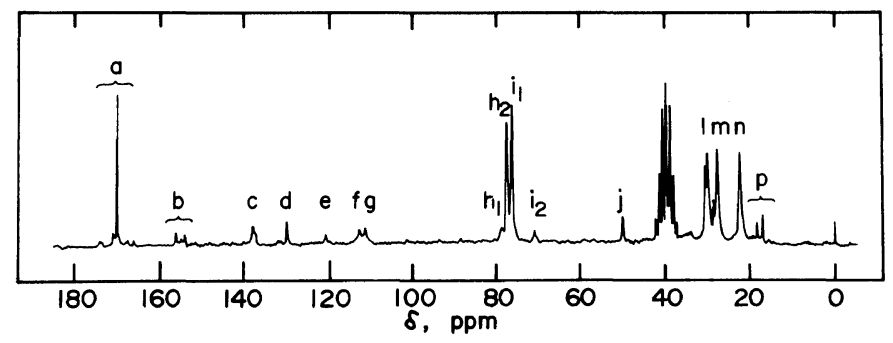

Figure 1. ${ }^{13} \mathrm{C}$ NMR spectrum of polyamide obtained by the anionic polymerization of $\mathrm{BOL}$ using tolylene-2,4-diisocyanate as an activator followed by a reaction with ethylenediamine $\left(M_{n}, 1380 ; 10 \%\right.$ $\mathrm{Me}_{2} \mathrm{SO}-d_{6}$ solution; $60^{\circ} \mathrm{C} ; 25 \mathrm{MHz}$ ).

The activator residue was determined by UV spectroscopy which showed that most of the TDI reacted with $\mathrm{BOL}$ anions and were introduced into the polyBOL chains. From the results of volumetric titration, the carboxyl groups at the polymer ends should have been replaced by amino groups. But the observed number of amino groups exceeded twice the amount of activator residue, especially in the reaction with EDA at higher temperature. Excess EDA readily attacks the amide carbonyl groups in the repeating units, as well as the carbonyl groups in the acyllactam-type polymer ends, at higher temperature as shown in eq 5 .
The aminolysis should be also accompanied by the introduction of amino groups to the newly resulting polymer ends.

In any event, the anionic polymerization of lactams is usually prevented by a trace amount of moisture, which should decrease the concentration of the monomer anion while probably not destroying the acyllactam-type growing species. Therefore, the reaction of the polymer ends with EDA should not be affected by the existence of a trace amount of water. Any side reactions can be easily suppressed in the anionic polymerization of BOL, because they polymerize under relatively mild conditions.

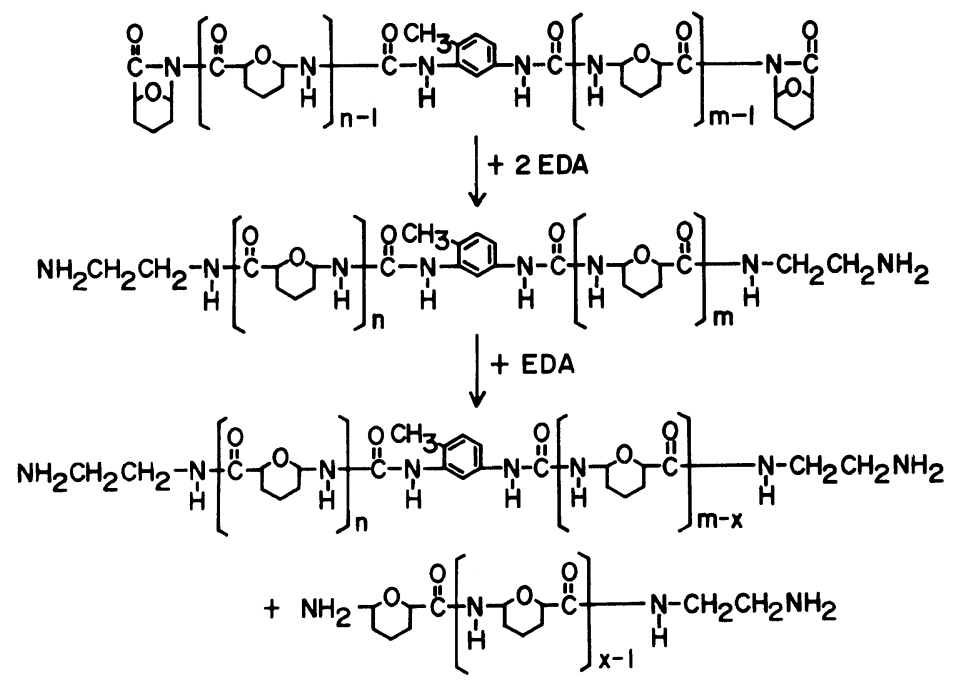


Consequently amino groups may be introduced directly and quantitatively onto the ends of the polyBOL molecules by reacting with EDA following polymerization.

Acknowledgement. This work was supported in part by a Grant-in-Aid for Scientific Research from the Ministry of Education, Science and Culture of Japan.

\section{REFERENCES}

1. H. Sumitomo, K. Hashimoto, and M. Ando, J. Polym. Sci., Polym. Lett. Ed., 11, 635 (1973).

2. H. Sumitomo and K. Hashimoto, Macromolecules, 10, 1327 (1977).

3. K. Hashimoto and H. Sumitomo, Macromolecules, 13, 786 (1980).

4. K. Hashimoto and H. Sumitomo, J. Polym. Sci., Polym. Chem. Ed., 21, 397 (1983).

5. H. Sumitomo, K. Hashimoto, and Y. Betsuda, Kobunshi Ronbunshu, 39, 807 (1982).

6. H. Sumitomo and K. Hashimoto, Kobunshi Ronbunshu, 34, 747 (1977).

7. H. Sumitomo, K. Hashimoto, and T. Ohyama, Polym. Bull., 1, 133 (1978).

8. T. Matsukura, T. Kinoshita, A. Takizawa, Y.
Tsujita, H. Sumitomo, and K. Hashimoto, Kobunshi Ronbunshu, 35, 803 (1978).

9. H. Sumitomo, K. Hashimoto, and T. Ohyama, Polym. Bull., 1, 635 (1979).

10. H. Sumitomo and K. Hashimoto, "Contemporary Topics in Polymer Science," Vol. 4, W. J. Bailey and T. Tsuruta Ed., Plenum, New York, in press.

11. R. Milkovich, "Anionic Polymerization. Kinetics, Mechanism, and Synthesis," J. E. McGrath Ed., ACS Symp. Ser., 166, 41 (1981) and references therein.

12. E. J. Goethals and M. A. Vlegels, Polym. Bull., 4, 521 (1981).

13. J. Sierra-Vargas, P. Masson, G. Beinert, P. Rempp, and E. Franta, Polym. Bull., 7, 277 (1982).

14. M. Takaki, R. Asami, and T. Kuwabara, Polym. Bull., 7, 521 (1982).

15. M. Maeda and S. Inoue, Makromol. Chem., Rapid Commun., 2, 537 (1981).

16. T. Yasuda, T. Aida, and S. Inoue, Polym. Prepr. Jpn., 31, 1221 (1982).

17. Y. Kawakami, Y. Miki, T. Tsuda, R. A. Murthy, and Y. Yamashita, Polym. J., 14, 913 (1982).

18. H. Sekiguchi, Bull. Soc. Chim. Fr., 1827 (1960).

19. H. K. Hall, Jr., M. K. Brandt, and R. M. Mason, J. Am. Chem. Soc., 80, 6420 (1958).

20. M. Sela and A. Berger, J. Am. Chem. Soc., 77, 1893 (1955). 